\title{
Apocrine hidrocystoma arising from a nevus sebaceous: A case report
}

\author{
Smita Masamatti1,*, Vijaya. C. ${ }^{2}$ \\ ${ }^{\mathbf{1}}$ Assistant Professor, ${ }^{2}$ Professor and Head, Dept. of Pathology, Sapthagiri Medical College and Hospital, Karnataka, India \\ *Corresponding Author: \\ Email: smitamas@gmail.com
}

Received: $17^{\text {th }}$ October, 2017

Accepted: $14^{\text {th }}$ December, 2017

\begin{abstract}
Apocrine hidrocystoma (AHC) are benign adnexal cystic tumours of the skin. They are uncommon and are usually found in the head and neck area. Nevus sebaceous (NS) is a hamartoma which is present since birth and is associated with many benign and malignant tumours such as trichoblastoma, trichilemmoma, sebaceoma, nevocellular nevi, keratoacanthoma, basal cell carcinoma etc. Apocrine hidrocystoma arising from a nevus sebaceous located over scalp region is extremely rare with less than five cases being reported till date. We report an interesting case of a 55 year old male who presented with a nodule over the scalp. A clinical diagnosis of sebaceous cyst was made. On histopathological examination, it turned out to be apocrine hidrocystoma arising in the background of nevus sebaceous.
\end{abstract}

Keywords: Benign, Hidrocystoma, Nevus sebaceous, Scalp.

\section{Introduction}

Apocrine hidrocystoma or cystadenomas are benign adenomatous cystic tumours of skin. They originate from the secretory portion of apocrine sweat glands. It was first described by Mehergan ${ }^{1}$ in 1964 as a benign neoplasm located on the face. AHC is an uncommon cystic lesion and is mostly solitary but multiple lesions have also been documented in the literature. They occur in the head and neck region. Other less common sites being, axilla, plams, scalp, chest and penis. Apocrine cystic lesions which have true papillary projections are referred as apocrine cystadenoma rather than apocrine hidrocystoma. ${ }^{2}$ Here we present an uncommon case of apocrine hidrocystoma arising in the background of nevus sebaceous, which was situated over scalp, again an unusual site for this tumour.

\section{Case Report}

A 55 year old man presented with a tiny nodule over scalp since birth, now complaing of irritation and slight enlargement of the swelling since past 15 days. On examination a well defined cystic nodule covered with few hair measuring about $2 \times 1 \mathrm{cms}$ located over scalp was noted. A clinical diagnosis of sebaceous cyst was made. Excision biopsy of the swelling was done and sent for histopathological examination. Gross examination showed a tense cystic swelling covered by skin bearing few hairs. Cut section showed a well defined cyst measuring $0.8 \times 0.5 \mathrm{cms}$ containing clear fluid (Fig. 1). Microscopy showed a multilocular cyst which was lined by inner columnar and outer myoepithelial cells (Fig. 2). The columnar cells at few places showed decapitation secretions (Fig. 3).The overlying upper dermis showed multiple immature sebaceous glands (Fig. 4). The patient showed no signs of recurrence after surgery during 3 months of follow up period.

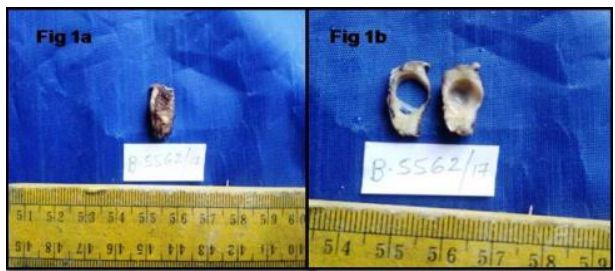

Fig. 1: Gross picture showing the skin covered cystic swelling measuring about $2.5 \times 1 \mathrm{cms}$ (fig 1a). Cut section showing a well defined cyst (fig 1b)

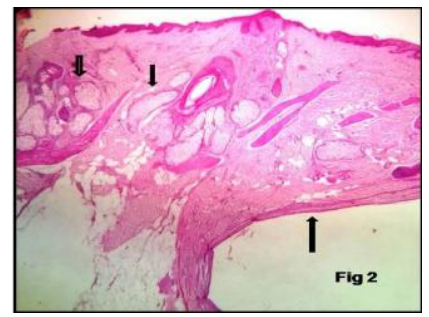

Fig. 2: Microphotograph showing skin with a cyst lined by flattened epithelium (big arrow). The overlying dermis shows multiple immature sebaceous glands (small arrows, $x 100$, H \& E)

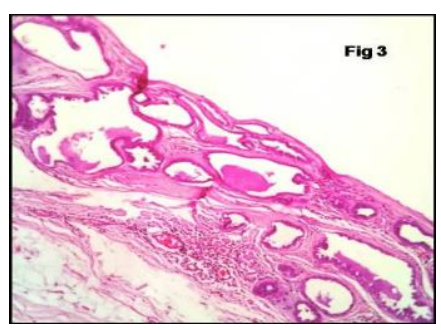

Fig. 3: Microphotograph showing a multiloculated cyst containing eosinophilic secretions $(x 100, \mathrm{H} \& \mathrm{E})$ 


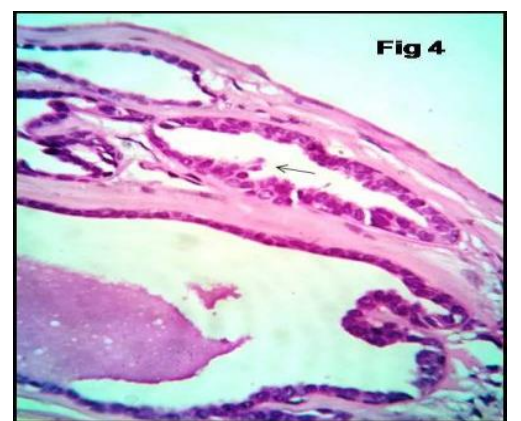

Fig. 4: Microphotograph showing the lining columnar cells with decapitation secretions (pointing arrow, $\mathrm{x} 400, \mathrm{H} \& \mathrm{E}$ )

\section{Discussion}

Nevus sebaceous of Jadassohn or organoid nevus, is a hamartoma comprised predominantly of sebaceous glands. Albrecht, in 1904 used the term hamartoma. These are nothing but collection of abnormal number of normal cells. They can be epidermal or dermal in location. ${ }^{3}$ Nevus sebaceous usually presents as a linear yellow, waxy, hairless verrucous plaque. They are present since birth and as the person ages; it undergoes surface changes, which was also noted in the present case. Many tumours arise from NS, the most common being, trichoblastoma, sebaceoma, nevocellular nevi, keratoacanthoma, seborrheic keratosis, syringocystadenoma papilliferum, trichilemmoma basal cell carcinoma etc. ${ }^{4}$

Hidrocystomas also called as sudoriferous cysts are uncommon benign adnexal sweat gland tumours. They occur singly or sometimes multiple lesions located especially over the eyelids. Other locations being, chest, scalp, palms and penis. ${ }^{5}$ They are characteristically asymptomatic and have an average diameter of 1.5 to $15 \mathrm{~mm}$, cystic and dome shaped lesions with a slight blue brown pigmentation. Giant apocrine hidrocystomas have also been described previously in the literature. Though eccrine or apocrine, hidrocystomas have same clinical appearances. Apocrine type usually produces oily, foamy secretions where as eccrine type produces watery secretions. Histopathologically, AHC show multiple cystic spaces with focal papillary projections where as eccrine hidrocystomas have single cavity with no papillary projections and is lined by one or two layers of cuboidal epithelial cells. ${ }^{6}$

Proliferative outgrowth and adenomatous hyperplasia are usually not seen. Proliferative features in these lesions however have been described previously in the literature and these lesions have a benign course despite showing cellular atypia and pleomorphism. Jonathan $\mathrm{L}$ Yao et $\mathrm{al}^{7}$ reported ER, PR and neuroendocrine positivity in AHC and designated them as AHC with proliferative features. Many cases of AHC documented benign apocrine hyperplasia. Few cases reported epidermoid metaplasia in apocrine cystadenomas which should not be confused with squamous cell carcinoma. ${ }^{8}{ }^{8}$ Some cases of pigmented AHC have also been reported which showed the evidence of melanin as the underlying mechanism of pigmentation. $^{7}$

Clinically hidrocystomas simulate heamangioma, lymphangiomas, molluscum contagiosum, epithelial inclusion cyst and atypical basal cell carcinoma. ${ }^{10}$

Multiple AHC may be associated with two rare inherited syndromes such as Schopf-schulz -passarge syndrome and Goltz -Gorlin syndrome. ${ }^{9}$ No such associations were noted in the present case.

\section{Conclusion}

This is a very rare case and to our knowledge only less than 5 such cases have been reported, this being the second case report from India. Hence this case is presented because of its rarity.

\section{References}

1. Mehergan AH. Apocrine cystadenoma; a clinicopathologic study with special reference to the pigmented variety. Arch Dermatol 1964;90:274-9.

2. Gurkan Kayabasoglu MD, Oznur Akidil MD. A rare pathology of post auricular region: Apocrine hidrocystoma. Int J clin Dermatol Res. 2014;2(6):34-36.

3. Way SC. Hamartoma of the skin; a case report. J Invest Dermatol. 1948: 10189-96.

4. Tejaswi C, Rangaraj M, Karthikeyan K. Apocrine hidrocystoma arising from nevus sebaceous on the scalp. Indian dermatol online J. 2016;7:111-3.

5. Avinash P, Mridula P, Niranjan K, Vandana GU. Recurrent giant apocrine hidrocystoma of the eyelid: A case report. Egyptian dermatology online journal.2014;10(1):10.

6. Vashi N, Mandal R. Giant multiloculated apocrine hidrocystomas. Dermatol online J.2010;16:16.

7. Yao JL, Phelps RG. Apocrine hidrocystoma with proliferative features: Apocrine cystadenoma. SM J Clin Pathol. 2017;2(1):1007.

8. Marsch WC. Epidermoid metaplasia in apocrine cystadenoma of the penis. An ultrastructural analysis. Arch Dermatol Res. 1984;276(3):170-7.

9. Shukla S, Patiri K, Pujani M, Komal SB. Bilateral multiple axillary apocrine hidrocystomas accompanied by apocrine hyperplasia: A rare presentation. Indian J Pathol Microbiol. 2014;57:281-3.

10. Sheth HG, Raina J. Giant eccrine hidrocystoma presenting with unilateral ptosis and epiphora. Int Opthalmol. 2008;28:429-31. 